\title{
Editorial
}

\section{Modified Kuppuswamy socioeconomic scale updated for the year 2021}

\author{
Sheikh Mohd Saleem ${ }^{1, *}$, Shah Sumaya Jan ${ }^{2}$ \\ ${ }^{1}$ Individual Public Health Researcher, Srinagar, Jammu and Kashmir, India \\ ${ }^{2}$ Dept. of Anatomy, Government Medical College, Srinagar, Jammu and Kashmir, India
}

\section{A R T I C L E I N F O}

Article history:

Received 01-03-2020

Accepted 17-03-2021

Available online 10-04-2021

\begin{abstract}
A B S T R A C T
Socioeconomic status (SES) is one among important indicators to evaluate the health status and nutritional status of a family. It is a position attained by any individual within a system of hierarchical social structure. Various attempts have been done in past by eminent scholars and medical scientists to formulate a group of composite indexes to determine SES of an individual or a family living in urban or rural areas. The scales have included various composite indexes to take into account details pertaining to an individual or any family. Among all the available SES, the most widely used and popular scale in our country is "Modified Kuppuswamy SES" which is mostly used for urban areas. In this paper, we have aimed at revising and providing an "Updated Modified Kuppuswamy SES" for the year 2021. The scale was initially developed by Kuppuswamy in the year 1976 including index parameters like education, occupation, and total income which was further modified in later years to include head of families educational status, occupational status and overall aggregate income of the whole family, pooled from all sources. The Kuppuswamy SES has included 3 parameters and each parameter is further classified into subgroups and scores have been allotted to each subgroup which have been defined later in this paper. The total score of Kuppuswamy SES ranges from 3-29 and it classifies families into 5 groups, "upper class, upper middle class, lower middle class, upper lower and lower socio-economic class." Due to limitations, the Kuppuswamy SES needs regular update for income levels which is based on changing CPI values which makes the scale vulnerable to fluctuations over time.
\end{abstract}

(c) This is an open access article distributed under the terms of the Creative Commons Attribution License (https://creativecommons.org/licenses/by/4.0/) which permits unrestricted use, distribution, and reproduction in any medium, provided the original author and source are credited.

\section{Introduction}

Socioeconomic status (SES) is one among important indicators to evaluate the health status and nutritional status of a family. The socio-economic status may be defined as "a position attained by any individual within a system of hierarchical social structure". ${ }^{1}$ SES has a major role to play in seeking health care services, accessibility issues, affordability costs, acceptance by beneficiaries and overall utilization of services by the people. ${ }^{2}$ The SES of any community has an influence on morbidity and mortality patterns in that community or geographic region. Mostly in scientific and social studies, many times determining patient's SES sometimes help in arriving diagnosis of an

\footnotetext{
* Corresponding author.

E-mail address: saleem.900@gmail.com (S. M. Saleem).
}

individual or family. That is why SES is always a prerequisite in history taking for health care individuals.

Various attempts have been done in past by eminent scholars and medical scientists to plan a group of composite indexes to determine SES of an individual or a family living in urban or rural areas. The worth mentioning among those include, "Rahudkar scale in the year 1960, B. J Prasad scale in 1961, Udai Parikh scale in 1964, Jalota scale in the year 1970, Kuppuswamy scale in 1976 and Bhardwaj scale recently in the year $2001 .^{3}$

All the scales have included various composite indexes to consider details pertaining to an individual or any family. Many scales have included scoring systems and later on classified individuals or families based on various categories. The scales have been formulated individually 
Table 1: Occupation of the Head of the family

\begin{tabular}{llc} 
S. No. & Occupation of the Head & Score \\
1 & Legislators, Senior Officials \& Managers & 10 \\
2 & Professionals & 9 \\
3 & Technicians and Associate Professionals & 8 \\
4 & Clerks & 7 \\
5 & Skilled Workers and Shop \& Market Sales Workers & 6 \\
6 & Skilled Agricultural \& Fishery Workers & 5 \\
7 & Craft \& Related Trade Workers & 4 \\
8 & Plant \& Machine Operators and Assemblers & 3 \\
9 & Elementary Occupation & 2 \\
10 & Unemployed & 1 \\
\hline
\end{tabular}

Table 2: Education of the Head ofthe family

\begin{tabular}{llc}
\hline S. No. & Education of the Head & Score \\
1 & Profession or Honours & 7 \\
2 & Graduate & 6 \\
3 & Intermediate or diploma & 5 \\
4 & High school certificate & 4 \\
5 & Middle school certificate & 3 \\
6 & Primary school certificate & 2 \\
7 & Illiterate & 1 \\
\hline
\end{tabular}

Table 3: Total monthly income of the family

\begin{tabular}{lcccc}
\hline S. No. & $\begin{array}{c}\text { Updated Monthly } \\
\text { Family Income in } \\
\text { Rupees (2012) }\end{array}$ & $\begin{array}{c}\text { Updated Monthly } \\
\text { Family Income in } \\
\text { Rupees (2018) }\end{array}$ & $\begin{array}{c}\text { Updated Monthly } \\
\text { Family Income in } \\
\text { Rupees (2020) }\end{array}$ & $\begin{array}{c}\text { Updated Monthly } \\
\text { Family Income in } \\
\text { Rupees (2021) }\end{array}$ \\
1 & $\geq 30,375$ & $\geq 126,360$ & $\geq 199,862$ & $\geq 123,322$ \\
2 & $15,188-30,374$ & $63,182-126,359$ & $99,931-199,861$ & $61,663-123,321$ \\
3 & $11,362-15,187$ & $47,266-63,181$ & $74,755-99,930$ & $46129-61,662$ \\
4 & $7594-11,361$ & $31,591-47,265$ & $49,962-74,755$ & $30,831-46,128$ \\
5 & $4556-7593$ & $18,953-31,590$ & $29,973-49,961$ & $18,497-30,830$ \\
6 & $1521-4555$ & $6327-18,952$ & $10,002-29,972$ & $6,175-18,496$ \\
7 & $\leq 1520$ & $\leq 6326$ & $\leq 10,001$ & $\leq 6174$ \\
\hline
\end{tabular}

Table 4: Kuppuswamy socio-economic status scale 2021

\begin{tabular}{llc}
\hline S. No. & Score & Socioeconomic Class \\
1 & $26-29$ & Upper (I) \\
2 & $16-25$ & Upper Middle (II) \\
3 & $11-15$ & Lower Middle (III) \\
4 & $5-10$ & Upper Lower (IV) \\
5 & $<5$ & Lower (V) \\
\hline
\end{tabular}

for urban and rural areas. The most common indexes taken into account include total income, educational status, and occupation. ${ }^{4}$ Among various scales for determining SES, the most widely and popularly used scales in India include "Updated Modified Kuppuswamy SES" which is mostly used for urban areas. ${ }^{5}$ However, because of the ongoing invasive economic growth and socioeconomic evolution over these years, the available SES have rendered inefficient in serving their usual purpose. For this reason, they need regular revisions over time to serve their purpose in ascertaining the SES of an individual or any family.
In this paper, we have aimed at revising and providing an "Updated Modified Kuppuswamy SES" scale for the year 2021.

\section{Modified Kuppuswamy SES scale}

This scale was devised by Kuppuswamy and is the most widely used scale for determining the socio-economic status of an individual or a family in urban areas. ${ }^{6}$ Initially, the scale was formulated for determining SES of an individual, but later on, it was modified to determine SES of a family rather than an individual. ${ }^{7}$ The scale was initially 
developed by Kuppuswamy in the year 1976 including index parameters like education, occupation, and total income which was further modified in later years to include head of families' educational status, occupational status and overall aggregate income of the whole family, pooled from all sources. ${ }^{8}$ The Kuppuswamy SES has included 3 parameters, and each parameter is further classified into subgroups and scores have been allotted to each subgroup which have been defined later in this paper. The total score of Kuppuswamy SES ranges from 3 to 29 and it classifies families into 5 groups, "upper class, upper middle class, lower middle class, upper lower and lower socio-economic class." The scale has been revised interminable over the past years because the parameter of overall income of the family from all the sources scale loses its pertinence following the devaluation in the worth of Indian rupee while the occupation of the head of family and education of the head of the family remains the same with time.

In order to carry out and perform the regular revision of the scale, the income scale in the Kuppuswamy SES is revised, "as per changes in the consumer price index (CPI) for industrial workers as projected by the central ministry of statistics and programme implementation on their website. ${ }^{9 "}$ The values of the CPI are "explicated in reference to a base year". As per the Labour Bureau, Government of India, "the current base year to be considered is 2012". ${ }^{10}$ An update of Kuppuswamy SES 2018 has used the latest base year for calculation purposes and has effectively determined correct income slabs. ${ }^{11}$ Here in this paper, we will use 2012 base year for calculating the income level of families to determine their socioeconomic status.

For calculation CPI, the current inflation rate of January 2021 i.e.: 4.06 has been taken into account. ${ }^{12}$ If we multiply the generated income scale values of the year 2012 with the conversion factor of 4.06 that will update the Kuppuswamy SES scale for January $2021 .^{3}$ The inflation rate is calculated using the formula $[(b-a / a) \times 100]$, where ' $b$ ' is the CPI of current year and ' $a$ ' is the CPI of last year. ${ }^{13}$ Kindly refer to Tables 1, 2, 3 and 4 for "Updated Kuppuswamy socioeconomic scale 2021".

Though the Kuppuswamy SES is most widely and favorite scale used by social scientists, researchers in community-based and hospital-based studies. It too has some limitations which render the scales sensitivity in assessing the socioeconomic status of a family. Those include consideration of educational status and type of occupation of the head of the family for calculation of socioeconomic status, which is completely unsuitable, taking the current scenario into consideration. Moreover, the scale needs the regular update and is based on changing CPI values, which makes the scale vulnerable to fluctuations in income levels.

\section{Source of Funding}

None.

\section{Conflict of Interest}

None.

\section{References}

1. Miner L, Bolding P, Hilbe J, Goldstein M, Hill T, Nisbet R, et al. Socioeconomic Status - an overview I ScienceDirect Topics [Internet] Available from: https://www.sciencedirect.com/topics/medicine-anddentistry/socioeconomic-status.

2. Institute of Medicine (US) Committee on Assuring the Health of the Public in the 21st Century. The Future of the Public's Health in the 21st Century. Washington (DC): National Academies Press (US); 2002. 5, The Health Care Delivery System. Available from: https://www.ncbi. nlm.nih.gov/books/NBK221227/.

3. Singh T, Sharma S, Nagesh S. Socio-economic status scales updated for 2017. Int J Res Med Sci. 2017;5(7):3264. 101:10.18203/23206012.1jrms20173029

4. Masthi N, Gangaboraiah, Kulkarni P. An exploratory study on socio economic status scales in a rural and urban setting. J Family Med Prim Care. 2013;2(1):69-73. 101:104-103/2249-4863-100952

5. Bairwa M, Rajput M, Sachdeva S. Modified kuppuswamy's socioeconomic scale: social researcher should include updated income criteria, 2012. Indian J Community Med. 2013;38(3):185-6. doi: $10.4103 / 0970-0218.116358$

6. Shaikh Z, Pathak R. Revised Kuppuswamy and B G Prasad socioeconomic scales for 2016. Int J Community Med Public Health. 2017;4(4):997. đo1:10.18203/2394-6040.11 cmph20171313.

7. Modified Kuppuswamy Scale I PSM Made Easy [Internet]. [cited 2021 Mar 2]. Available from: http://www.ihatepsm.com/blog/modifiedkuppuswamy-scale.

8. Kuppuswamy B. Manual of socio-economic status scale (urban) Delhi; Manasyan; 1981.

9. Ministry of Statistics and Program Implementation I Government of India [Internet]; 2005. Available from: http://www.mospi.gov.in/.

10. Labour Bureau Main [Internet]. Available from: http://labourbureau. gov.in/.

11. Saleem SM. Modified Kuppuswamy scale updated for year 2018 . Indian J Res. 2018;7(3):6-7.

12. India Inflation Rate | 2019 | Data | Chart | Calendar | Forecast I News [Internet]. Available from: https://tradingeconomics.com/india/ inflation-cpi.

13. McMahon. How Do I Calculate the Inflation Rate? [Internet]. Available from: https://inflationdata.com/inflation/Inflation_Articles/ CalculateInflation.asp.

\section{Author biography}

Sheikh Mohd Saleem, Consultant

Shah Sumaya Jan, Demonstrator

Cite this article: Saleem SM, Jan SS. Modified Kuppuswamy

socioeconomic scale updated for the year 2021. Indian J Forensic

Community Med 2021;8(1):1-3. 